\title{
Inspection planning by defect prediction models and inspection strategy maps
}

\author{
Elisa Verna $^{1} \cdot$ Gianfranco Genta $^{1} \cdot$ Maurizio Galetto $^{1} \cdot$ Fiorenzo Franceschini $^{1}$ (D)
}

Received: 10 March 2021 / Accepted: 21 June 2021 / Published online: 1 July 2021

(c) The Author(s) 2021

\begin{abstract}
Designing appropriate quality-inspections in manufacturing processes has always been a challenge to maintain competitiveness in the market. Recent studies have been focused on the design of appropriate in-process inspection strategies for assembly processes based on probabilistic models. Despite this general interest, a practical tool allowing for the assessment of the adequacy of alternative inspection strategies is still lacking. This paper proposes a general framework to assess the effectiveness and cost of inspection strategies. In detail, defect probabilities obtained by prediction models and inspection variables are combined to define a pair of indicators for developing an inspection strategy map. Such a map acts as an analysis tool, enabling positioning assessment and benchmarking of the strategies adopted by manufacturing companies, but also as a design tool to achieve the desired targets. The approach can assist designers of manufacturing processes, and particularly low-volume productions, in the early stages of inspection planning.
\end{abstract}

Keywords Quality control · Inspection planning · Inspection strategy map · Inspection design · Assembly · Low-volume production

\section{Introduction}

Manufacturing companies are increasingly focused on producing high-quality and fault-free products that meet customer needs. Defects in the final product, particularly those generated during the production process, can significantly affect the product itself, both in terms of quality and cost [1-3]. In this regard, designing effective and cost-efficient inspection strategies for the detection of defects and the reduction of quality-related costs has always been a great challenge and a crucial factor for achieving market competitiveness [4-8].

Fiorenzo Franceschini

fiorenzo.franceschini@polito.it

Elisa Verna

elisa.verna@polito.it

Gianfranco Genta

gianfranco.genta@polito.it

Maurizio Galetto

maurizio.galetto@polito.it

1 Department of Management and Production Engineering, Politecnico Di Torino, Corso Duca degli Abruzzi 24, 10129 Turin, Italy
A distinction between in-process and offline inspection strategies should be considered when designing inspections [9]. In in-process inspections, units are inspected during the production process [10-13], while in offline inspections, finished products are inspected after the production process is completed [10,14]. Although in-process inspections are considered more economical and effective than offline inspections, in some situations, they are impossible to perform, not adequate or not affordable [7, 10].

Several methods have been adopted in literature to design quality-inspections in mass productions, including simulations [15-17], cost-benefit models [18], optimisation and mathematical programming models [19-21]. However, when dealing with low-volume productions [22], such techniques may not be appropriate [23-28]. In literature, few studies investigated the design of offline inspection strategies which can be also suitable for low-volume manufacturing productions. In a recent study, a methodology to select the best compromise between the effectiveness and the affordability of alternative offline inspection strategies in a low-volume Additive Manufacturing (AM) production was proposed [7]. Regarding the design of in-process inspections, existing methods rely on the decomposition of the manufacturing process of interest into several steps, in which specific 
defects can occur $[4,29,30]$. Such models, apart from being used in mass production, are particularly relevant and beneficial for low volume production. In detail, Franceschini et al. (2018) proposed a practical methodology to guide quality designers in selecting the most effective and economically convenient inspection procedures. The proposed approach was applied to a structured case study concerning the lowvolume production of hardness testing machines [4]. Despite the originality and the practical implications of this study, suitable models for supporting the estimation of the variables involved, especially the probabilities of occurrence of defects in each process step, have not been closely examined. This limitation was overcome in the work of Genta et al. (2018), where models linking the assembly complexity with the operator-induced defect rate $[30,31]$ were implemented in order to get a priori predictions of the probability of occurrence of defects [29]. Such probabilities were then adopted for designing effective inspection procedures in the manufacturing of hardness testing machines. Nevertheless, a detailed analysis of the economic effects of the proposed inspection design was not addressed. Thus, a comprehensive study including the use of defect generation models and the assessment of inspection strategies effectiveness and costefficiency is still lacking. The purpose of this paper is to address this gap by proposing a general framework to quantitatively assess the adequacy of in-process inspection strategies from the point of view of the effectiveness and cost. The following research question (RQ) is specifically addressed:

RQ: How to develop a tool to support designers in choosing the most appropriate inspection strategy from an effectiveness and cost standpoint?

It should be pointed out that, in this study, an inspection strategy is defined as the combination of inspection methods used to perform quality controls in the different workstations of the assembly process. For instance, a strategy may require all workstations to be inspected or only some of them. Besides, workstations can be inspected using alternative methods, e.g., visual checks or mechanical tests. Therefore, adopting one strategy rather than another involves choosing which workstations to inspect and by which inspection method.

The approach herein proposed is based on the joint use of defect prediction models and specific "inspection maps". In detail, a pair of indicators depicting the effectiveness and cost of inspection strategies is used to construct a new support tool named "Inspection Strategy Map (ISM)". Two are the main purposes of ISM:

(i) analysing the positioning of different inspection strategies on the map, in terms of effectiveness and cost, allowing the designer to compare more alternatives (analysis tool); (ii) supporting the designer in determining the conditions of effectiveness and cost to allow an a priori inspection strategy positioning.

The framework and the tool proposed in this study were applied to the assembly of wrapping machines. Such a process can be classified as a low-volume production, being the total number of customised machines produced in a year, typically, of about 50 units.

This study may provide an opportunity to advance the understanding of the inspection planning process, especially for low-volume productions where traditional techniques are not exploitable. By ISM, engineers are driven to identify alternative inspection procedures in order to make the inspection strategy more effective and cost-efficient.

The remainder of the paper is organised into four sections. Section 2 summarises the major contributions related to the topic of the paper. In Sect. 3, the ISM tool is presented and discussed in detail. Section 4 describes an application of ISM to a case study related to the assembly of wrapping machines. Finally, Sect. 5 summarises the original contributions of this research.

\section{Conceptual background}

\subsection{Defect prediction models in inspection planning}

Several models were developed in the literature to predict defects of a final assembled product [30-39]. A large part of these models relies on the close relationship between assembly complexity and defectiveness rate related to each process step, also called workstation. These models can be used in a wide variety of applications, ranging from the electromechanical to the automotive sector.

In this study, a defect prediction model, developed for a low-volume production of wrapping machines, is adopted. It relies on the relationship between structural complexity and Defects Per Unit occurring in each ith workstation $\left(D P U_{i}\right)$ [38]. The predictor of this model is the product complexity related to the $i$ th workstation, evaluated according to the approach proposed by Alkan [40] and Sinha [41]:

$C_{i}=C_{1, i}+C_{2, i} \cdot C_{3, i}$

In Eq. (1), $C_{1, i}$ represents the sum of complexities of individual product parts in each $i$ th workstation. $C_{1, i}$ is calculated as shown in Eq. (2):

$C_{1, i}=\sum_{p=1}^{N_{i}} \gamma_{p i}$ 
Fig. 1 Connectivity structure of a product composed of three parts and its associated adjacency matrix $\boldsymbol{A}$

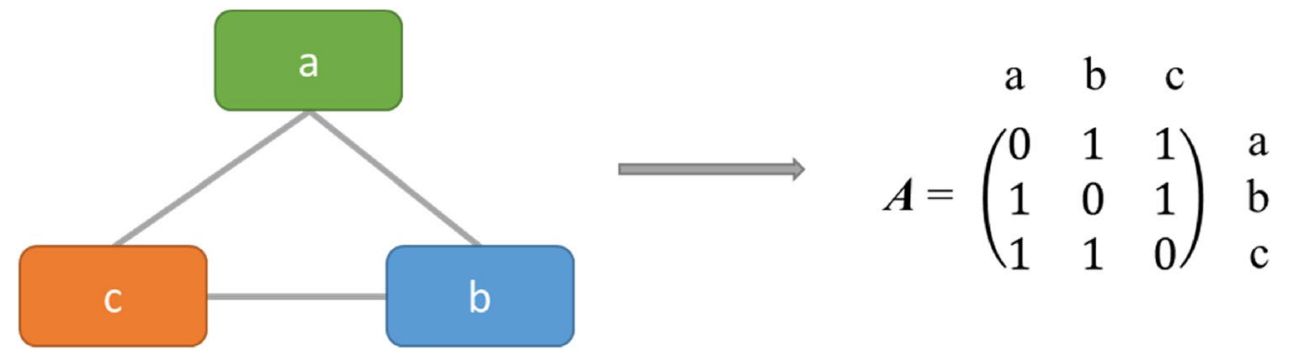

where, for each $i$ th workstation $(i=1, \ldots, m), N_{i}$ is the total number of product parts and $\gamma_{p i}$ is the handling complexity of part $p$, which can be estimated as a function of the standard handling time [40].

$C_{2, i}$ is defined as the complexity of connections related to the $i$ th workstation. It is the sum of the complexities of pairwise connections that exist in the product structure assembled in the $i$ th workstation, as follows:

$C_{2, i}=\sum_{p=1}^{N_{i}-1} \sum_{r=p+1}^{N_{i}} \varphi_{p r i} \cdot A_{p r i}$

where $\varphi_{p r i}$ is the complexity in achieving a connection between parts $p$ and $r$ of the $i$-th workstation. $\varphi_{p r i}$ can be estimated through the standard completion time of the connection between parts $p$ and $r$ in isolated conditions. Besides, $A_{p r i}$ defines the binary adjacency matrix representing the connectivity structure of the system, as indicated in Eq. (4): c), see Fig. 1. The standard handling time of each $p$-th part ( $p=1,2,3)$ is $\gamma_{p}=40 \mathrm{~s}$. According to Eq. (2), the handling complexity is $C_{1}=\sum_{p=1}^{3} \gamma_{p}=2 \mathrm{~min}$. The standard completion time of the connection between parts $p$ and $r(p=1,2$ and $r=p+1,2,3)$ is $\varphi_{p r}=80 \mathrm{~s}$. By implementing Eq. (3), the complexity of connections is $C_{2}=\sum_{p=1}^{2} \sum_{r=p+1}^{3} \varphi_{p r} \cdot A_{p r}=$ 4 min, since there are 3 connections between the parts. From the adjacency matrix $\boldsymbol{A}$ (see Fig. 1), the related graph energy is computed as the sum of its singular values, that are the absolute eigenvalues in case of symmetric matrix. In detail, two different eigenvalues of $\boldsymbol{A}$ are obtained, i.e., -1 with multiplicity of 2 and 2 . Thus, being the singular values the absolute eigenvalues of $\boldsymbol{A}$, then $E_{A}=1+1+2=4$. According to Eq. (5), $C_{3}=\frac{E_{A}}{N}=\frac{4}{3}=1.33$. Finally, by Eq. (1), the structural complexity is $C=C_{1}+C_{2} \cdot C_{3}=7.33 \mathrm{~min}$.

As an example, Table 1 reports, for each $i$-th workstation of the pre-stretching device of a wrapping machine (see next Sect. 4.1), the complexities $C_{1, i}, C_{2, i}$ and $C_{3, i}$, according

$A_{p r i}=\left\{\begin{array}{l}1 \text { if there is a connection between } p \text { and } r \text { in the ith workstation } \\ 0 \text { otherwise }\end{array}\right.$

Finally, $C_{3, i}$ is the topological complexity of the $i$-th workstation and represents the complexity related to the architectural pattern of the assembled product. It can be obtained from the matrix energy $E_{A i}$ of the adjacency matrix related to the $i$-th workstation, which is designated by the sum of the corresponding singular values $\delta_{p i}[41,42]$, as follows:

$C_{3, i}=\frac{E_{A i}}{N_{i}}=\frac{\sum_{p=1}^{N_{i}} \delta_{p i}}{N_{i}}$

where $E_{A i}$ stands for graph energy (or matrix energy) and $N_{i}$ stands for the number of parts in the $i$-th workstation (i.e., the number of nodes). It has to be clarified that, since the adjacency matrix is a symmetric matrix of size $N_{i}$ with the diagonal elements being all zeros, the singular values correspond to the absolute eigenvalues of the adjacency matrix [41, 43].

A pedagogical example referring to an assembly process made up of a single workstation is provided. The product to be assembled is composed of $N=3$ identical parts ( $\mathrm{a}, \mathrm{b}$ and respectively to Eqs. (2), (3) and (5), and the final assembly complexity $C_{i}$ derived by Eq. (1). $D P U_{i}$ and $C_{i}$ are related by the following power-law regression model [44]:

$D P U_{i}=3.05 \cdot 10^{-3} \cdot\left(C_{i}\right)^{1.58}$

Figure 2 illustrates the defect prediction model defined in Eq. (6) and the corresponding residual plots.

Identifying suitable defect prediction models is a key factor for providing practical assistance in the design, improvement and optimisation of an assembled product [31]. The adoption of reliable defect rate estimates can also successfully guide inspection designers in planning inspection strategies from early design phases $[4,7]$. Recent studies by the authors investigated the use of defect prediction models to obtain reliable estimates of the probability of occurrence of defective-workstation-outputs in assembly processes, particularly suitable for low-volume productions [29, 36, 38]. A workstation-output consists of a set of all units that goes thorough the workstation. The workstation-output is considered defective if at least one defect is found, regardless of 


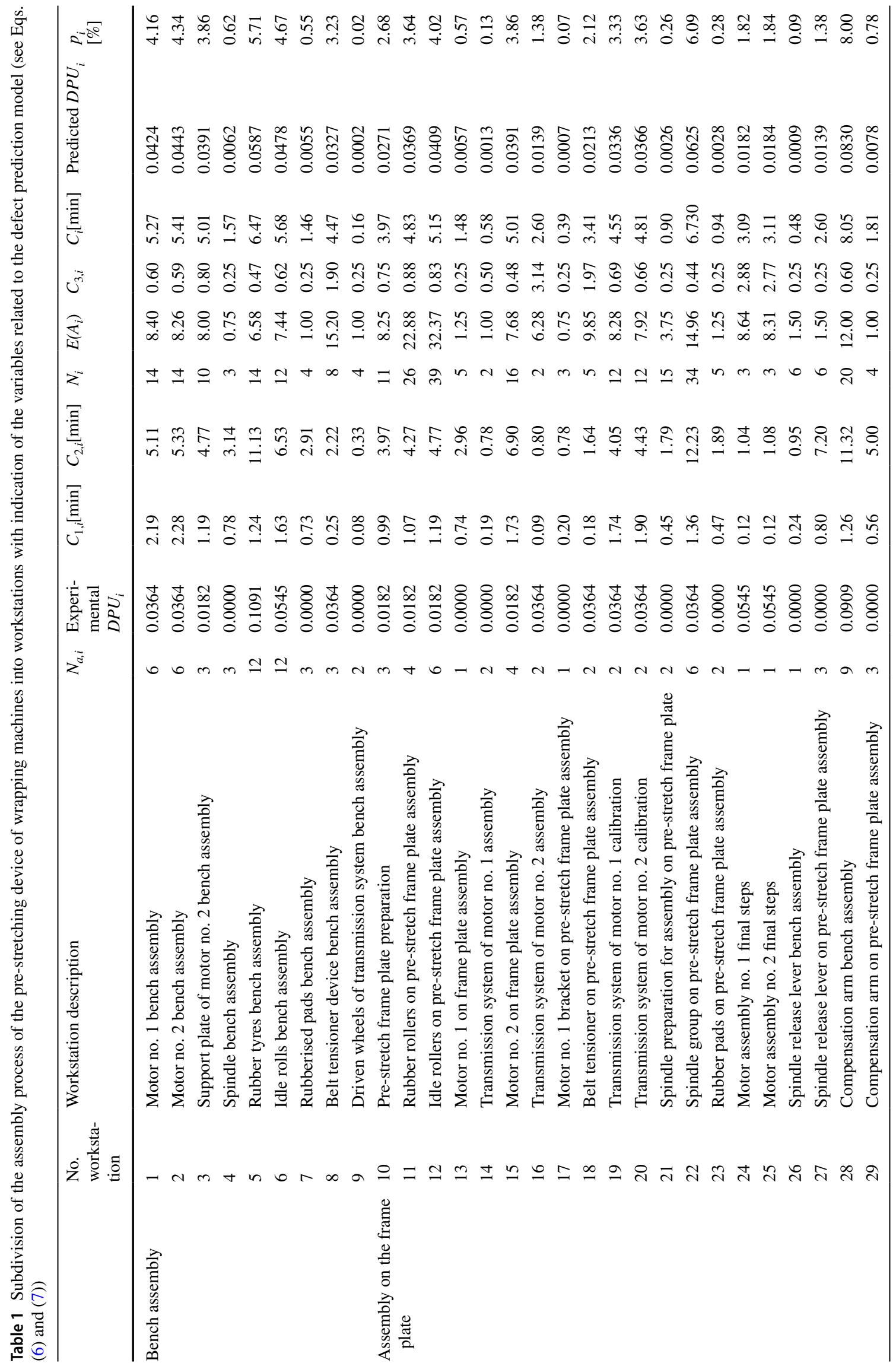


Fig. $2 D P U$ vs $C$ : a Regression model and experimental data, and $\mathbf{b}$ Residual plots

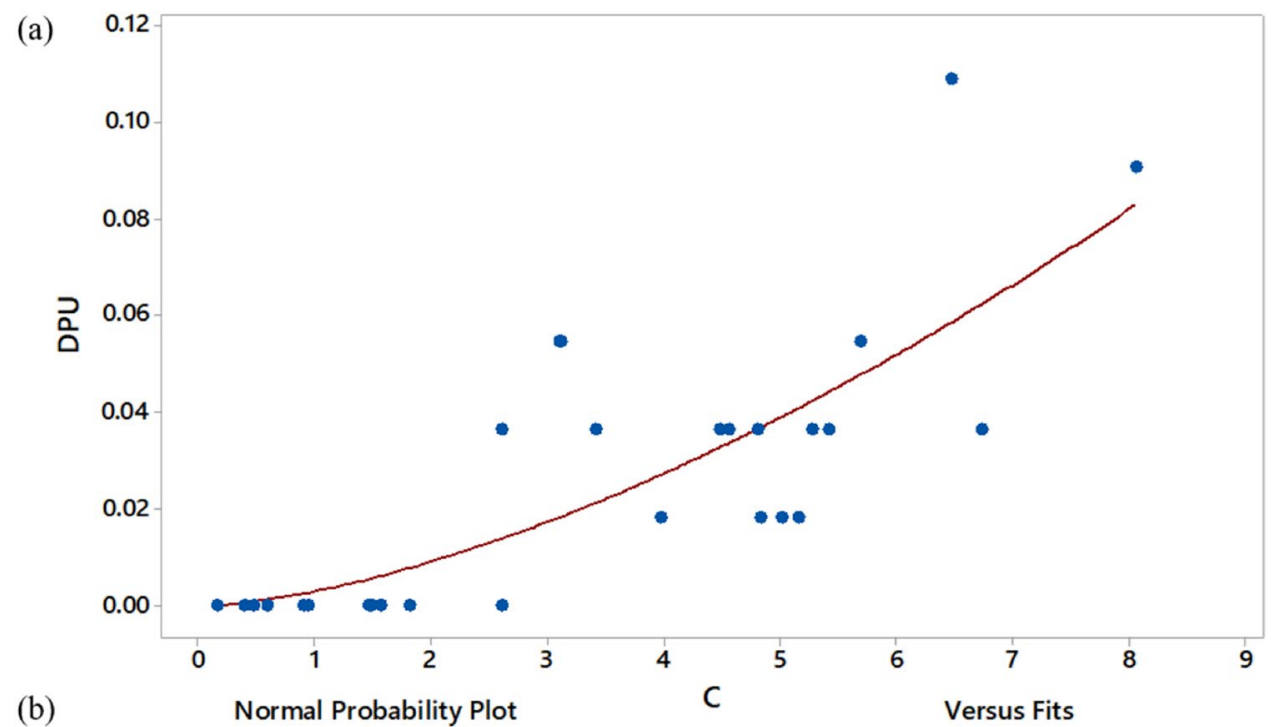

(b)
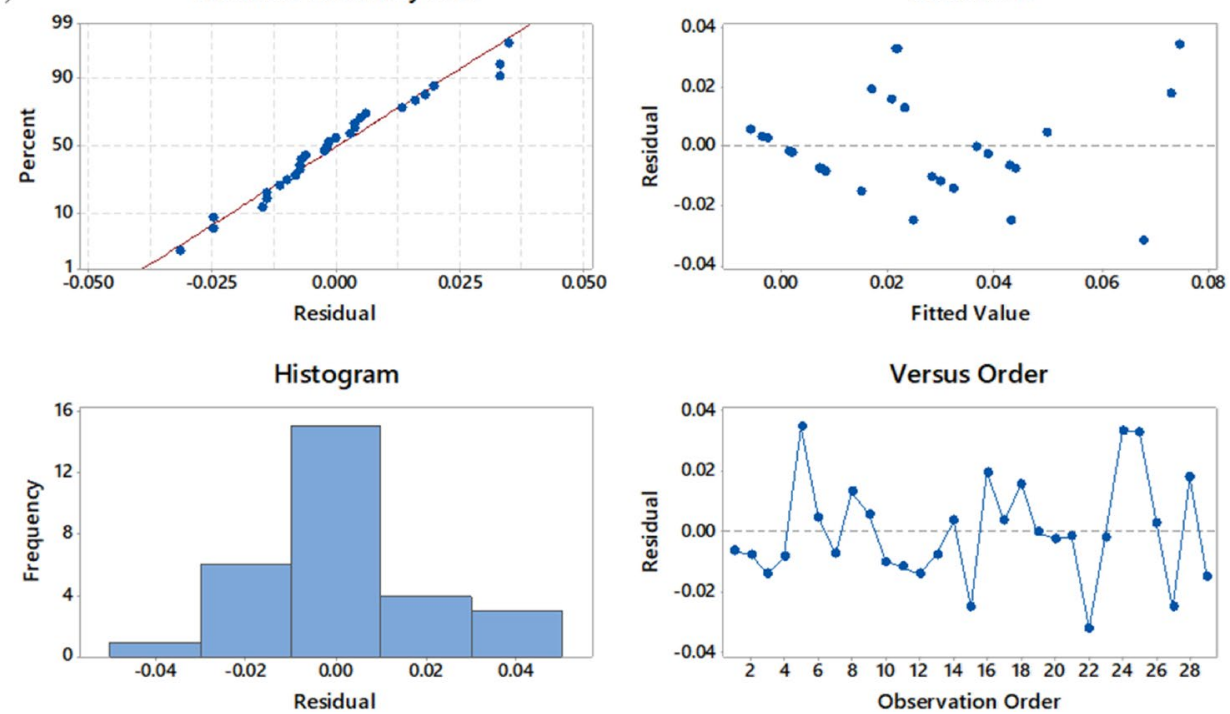

whether these defects are distributed among the workstation units. Accordingly, the probability of occurrence of at least one defect in each workstation $i$ represents the probability of occurrence of a defective-workstation-output $\left(p_{i}\right)$. In detail, knowing the $D P U_{i}$ (see Eq. 6) and the number of elementary operations $N_{a, i}$ (also called job elements) performed by operators in each $i$ th workstation, the probability of occurrence of a defective-workstation-output $p_{i}$ can be defined as [29]:

$p_{i}=1-\left(1-\frac{D P U_{i}}{N_{a, i}}\right)^{N_{a, i}}$

Table 1 shows the predicted $D P U_{i}$ and $p_{i}$ values for each $i$-th workstation of the pre-stretching device of a wrapping machine.

\subsection{Inspection strategy performances (effectiveness and total cost)}

As highlighted in the previous section, an overall assembly manufacturing process, in optimal settings condition, may be modelled by decomposing it into several process steps, also called workstations [4, 29, 30, 36]. Each of such workstations produces an outcome, henceforth called workstation-output, whose conformity can be tested through different inspection activities. Quality control activities are performed on the workstation-output according to the specific kind of defect to be detected. They include, for instance, dimensional verifications, visual checks, comparison with reference exemplars, mechanical tests, etc. [5, 45, 46]. The combination of the inspection activities performed on the workstations defines an 
inspection strategy for the assembly process. Inspection designers can choose between several alternative strategies to inspect an overall manufacturing process. For example, a strategy may require all workstations to be inspected or only some of them. Alternatively, the choice may concern a strategy where all workstations are inspected by visual checks or another one where only mechanical tests are performed, and so on.

When performing an inspection activity, two types of inspection errors may occur: there are a risk of detecting a defect when it is not present (type I error) and a risk of not detecting the defect when it is actually present (type II error). Although such risks can be reduced through sophisticated quality monitoring techniques, manual and/or automatic, they should not be neglected [47-49].

In the modelling of a manufacturing process and inspection strategy, each $i$ th workstation (where $i=1, \ldots, m$ ) can be associated to three variables [4]:

- $p_{i}$ : probability of occurrence of a defective-workstation-output in optimal operating conditions;

- $\alpha_{i}$ : probability of erroneously detecting as defective a non-defective-workstation-output (i.e., type-I inspection error);

- $\beta_{i}$ : probability of erroneously not detecting a defectiveworkstation-output (i.e., type-II inspection error).

The first variable, $p_{i}$, is strictly related to the quality of the process related to the $i$ th workstation. It should be emphasised that such defect probability is due to a physiological condition of the process; therefore, it is not affected by occasional failures or errors. On the other hand, the inspection errors $\alpha_{i}$ and $\beta_{i}$ depend on the quality of the inspection activity, that involves the inspection typology and procedure, the technical skills and experience of the operators, the environmental conditions, etc. [10, 14, $49,50]$. In practical applications, the variable $p_{i}$ may be estimated by using the defect prediction model shown in Eq. (7). On the other hand, $\alpha_{i}$ and $\beta_{i}$ can be estimated by the use of simulations, prediction models and/or empirical methods, based on historical data, previous experience on similar processes, and process knowledge [4, 29, 51].

A typical inspection strategy performance may be assessed by two inspection indicators which depict the overall effectiveness and economic convenience of an inspection strategy $[5,7,52,53]$. As explained in authors' recent studies [4, 29,51], the inspection effectiveness of an inspection strategy may be represented using a practical indicator, $D_{t o t}$, defining the mean total number of defective-workstation-outputs which are erroneously not detected after completing the overall inspection strategy, as follows $[4,29]$ :
$D_{\text {tot }}=\sum_{i=1}^{m} D_{i}=\sum_{i=1}^{m} p_{i} \cdot \beta_{i}$

where $D_{i}$ represents the mean number of actual defectiveworkstation-outputs undetected in the $i$-th workstation. The indicator $D_{t o t}$ is obtained by assuming that the variables $p_{i}, \alpha_{i}$ and $\beta_{i}$ related to both the same workstations and to different ones are uncorrelated.

The total cost related to the inspection strategy may be estimated by the total cost indicator, $C_{t o t}$, that includes the cost of the specific inspection activity, the necessary- and the unnecessary-repair costs, and the cost of undetected defects, as shown in Eq. (9) $[4,51]$. Since such indicator assesses the total cost related to the inspection strategy in use, it can be used as a proxy for the affordability of the inspection strategy.

$$
\begin{aligned}
C_{\text {tot }}= & \sum_{i=1}^{m} C_{\text {tot }, i} \\
= & \sum_{i=1}^{m}\left[c_{i}+N R C_{i} \cdot p_{i} \cdot\left(1-\beta_{i}\right)\right. \\
& \left.+U R C_{i} \cdot\left(1-p_{i}\right) \cdot \alpha_{i}+N D C_{i} \cdot p_{i} \cdot \beta_{i}\right]
\end{aligned}
$$

where:

- $C_{t o t, i}$ is the total cost related to the $i$ th workstation;

- $c_{i}$ is the cost of the control performed in the $i$ th workstation;

- $N R C_{i}$ is the Necessary-Repair Cost, namely the necessary cost for repairing/removing the defective-workstationoutputs (or in some cases the cost of rejection);

- $U R C_{i}$ is the Unnecessary-Repair Cost, i.e., the cost incurred when identifying false defective-workstationoutputs; e.g., despite there is no cost required for defective-workstation-outputs removal, the overall process can be slowed down, with a consequent extra cost.

- $N D C_{i}$ is the cost of undetected defective-workstationoutputs, namely the external failure costs related to the missing detection of defective-workstation-outputs, including legal fees related to customer lawsuits, loss of future sales from dissatisfied customers, product recalls, product return costs, after-sales repair costs, etc. [7].

Even this indicator is obtained under the assumption of absence of statistical correlation between the variables $p_{i}$, $\alpha_{i}$ and $\beta_{i}$ related both to the same workstations and to different ones.

The reliability of the two indicators of performance can be assessed by providing a quantitative estimation of their variability. To this aim, the method provided by the GUM (Guide to the expression of Uncertainty in Measurement) is used [54]. According to this approach, the uncertainty 
Fig. 3 Schematic representation of an inspection strategy map

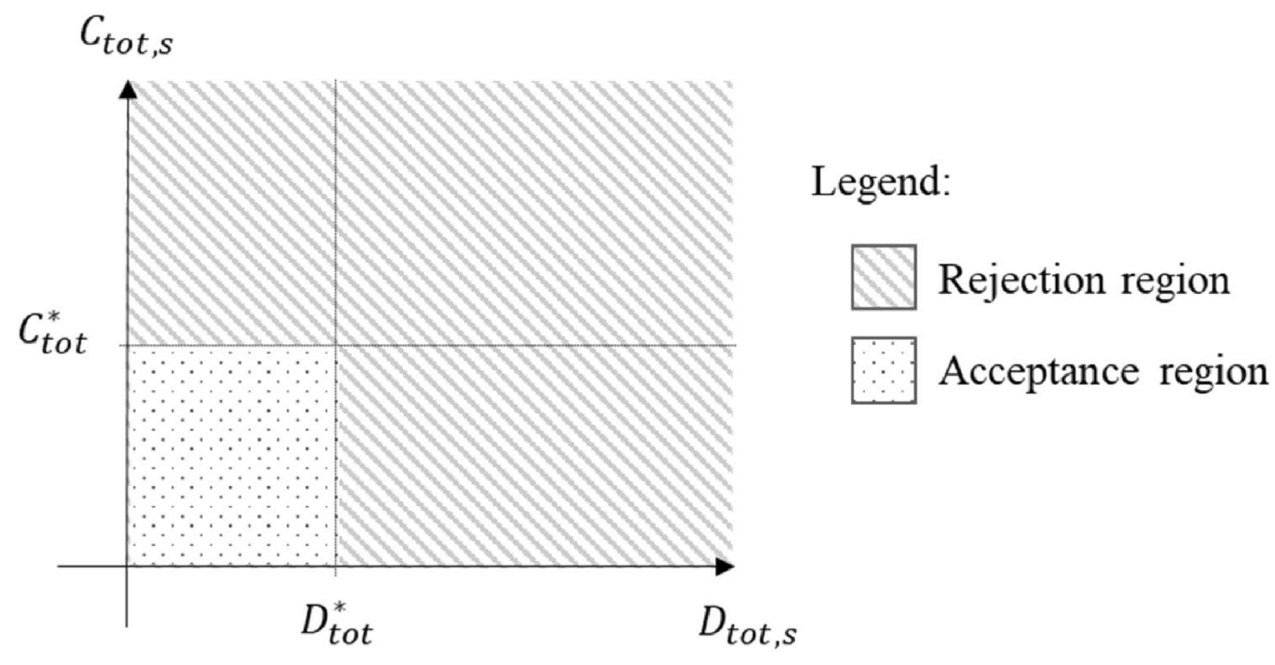

affecting all the model variables, i.e. $p_{i}, \alpha_{i}, \beta_{i}, c_{i}, N R C_{i}, U R C$ ${ }_{i}$ and $N D C_{i}$, can be combined and propagated to the resulting indicators $D_{t o t}$ and $C_{t o t}[54,55]$. A detailed description and implementation of the method is provided in the recent study of the authors [51]. Accordingly, the uncertainty, expressed in terms of variance, $V A R$, of the indicators of effectiveness and total cost is, respectively:

$$
\begin{aligned}
& \operatorname{VAR}\left(D_{t o t}\right)=\sum_{i=1}^{m}\left[\beta_{i}^{2} \cdot \operatorname{VAR}\left(p_{i}\right)+p_{i}^{2} \cdot \operatorname{VAR}\left(\beta_{i}\right)\right] \quad \text { (10) } \begin{array}{l}
\text { interval of } D_{\text {tot, }} \text { and } C_{\text {tot }} \\
\text { made with the thresholds }
\end{array} \\
& \operatorname{VAR}\left(C_{t o t}\right) \approx \sum_{i=1}^{m}\left[\left(N R C_{i}-N R C_{i} \cdot \beta_{i}-U R C_{i} \cdot \alpha_{i}+N D C_{i} \cdot \beta_{i}\right)^{2} \cdot \operatorname{VAR}\left(p_{i}\right)+\right. \\
& +\left(U R C_{i}-U R C_{i} \cdot p_{i}\right)^{2} \cdot \operatorname{VAR}\left(\alpha_{i}\right)+\left(-N R C_{i} \cdot p_{i}+N D C_{i} \cdot p_{i}\right)^{2} \cdot \operatorname{VAR}\left(\beta_{i}\right)+\operatorname{VAR}\left(c_{i}\right)+ \\
& \left.\quad+\left(p_{i}-p_{i} \cdot \beta_{i}\right)^{2} \cdot \operatorname{VAR}\left(N R C_{i}\right)+\left(\alpha_{i}-p_{i} \cdot \alpha_{i}\right)^{2} \cdot \operatorname{VAR}\left(U R C_{i}\right)+\left(p_{i} \cdot \beta_{i}\right)^{2} \cdot \operatorname{VAR}\left(N D C_{i}\right)\right]
\end{aligned}
$$

second threshold, $C^{*}{ }_{t o t}$, is a cost limit for the company, i.e. the maximum cost that the producer is willing to pay for the inspection strategy. Then, the following rules can be used to support inspection designers in the choice of the most appropriate inspection strategy according to their requirements.

For each $s$-th inspection strategy (where $s=1, \ldots, k$ ), a comparison between the upper limit of the $95 \%$ confidence interval $^{1}$ of $D_{t o t, s}$ and $C_{t o t, s}$, identified as $D_{t o t, s}^{U}$ and $C_{t o t, s}^{U}$, is made with the thresholds $D^{*}{ }_{t o t}$ and $C^{*}{ }_{t o t}$ :

\section{Inspection strategy maps (ISM)}

Overall, for each inspection strategy to be assessed and compared, the two performance indicators may be calculated by Eqs. (8) and (9). According to the scientific literature about Multi-Criteria Decision-Making (MCDM), several methods may be implemented to choose from different alternatives when multiple criteria and trade-offs are involved [56-59]. In the present study, a more straightforward and practical methodology is proposed to support quality inspection planning by Inspection Strategy Maps (ISMs). ISMs are defined on a plan whose axes are the two indicators $D_{t o t}$ and $C_{\text {tot }}$ (see Fig. 3). Each inspection strategy may be described by a point on the ISM.

A pair of thresholds (respectively $D^{*}{ }_{t o t}$ and $C^{*}{ }_{t o t}$ ) defined by the designer limits the values of the two indicators. $D^{*}{ }_{t o t}$ can be seen as a guarantee for the consumer because it represents the maximum average number of acceptable defective-workstation output remaining in the final product. The
(1) if $D_{t o t, s}^{U}<D^{*}$ tot and $C_{t o t, s}^{U}<C^{*}{ }_{t o t}$, the strategy may be selected: the strategy is therefore in the acceptance region (see Fig. 3);

(2) if $D_{t o t, s}^{U}>D^{*}{ }_{t o t}$ or $C_{t o t, s}^{U}>C^{*}{ }_{t o t}$, the strategy is located in the rejection region (see Fig. 3).

If more strategies lie in the acceptance region, and therefore their values of $D_{t o t}$ and $C_{t o t}$ are below the imposed thresholds, the designer can decide which strategy should be adopted. The preferred strategy is the one that minimises both $D_{t o t}$ and $C_{t o t}$. However, if among the alternatives no strategy minimises both indicators, the designer can choose whether minimising one or the other. Such choice strictly depends on the product specifications and the certification constraints imposed by the product application sector. For example, in medical or aerospace

\footnotetext{
1 A confidence interval gives an estimated range of values which is likely to include an unknown population parameter. In this study, the conventional 95\% confidence level is adopted in the analysis.
} 


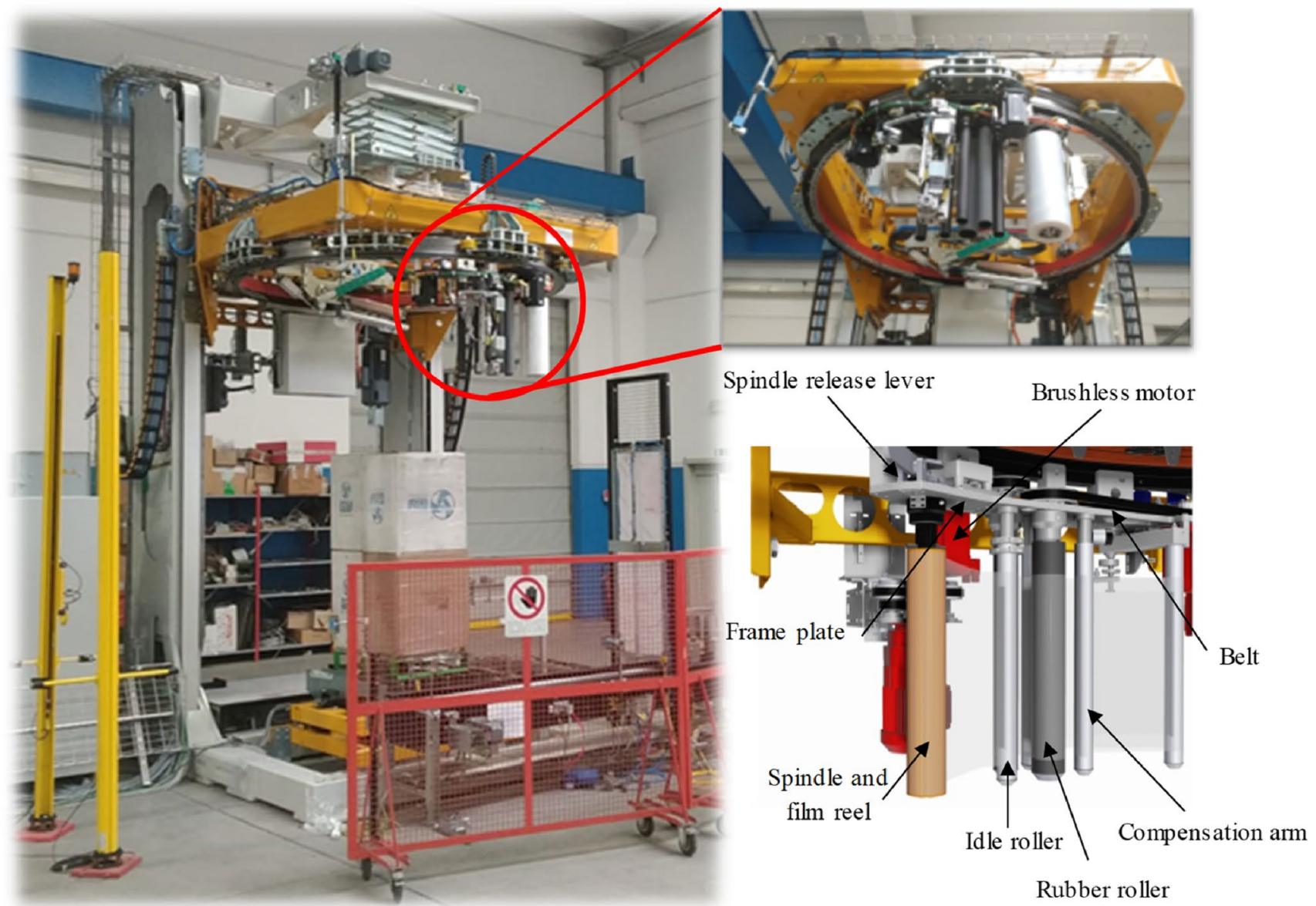

Fig. 4 Rotating ring wrapping machine produced by Tosa Group S.p.A. (Italy) with a focus on the pre-stretching device: bottom-frame image and front view of 3D CAD model with the indication of the main components

sectors, the producer may be more inclined to select the strategy that minimises $D_{t o t}$ instead of choosing the most cost-efficient one, because of the significant consequences external failures could have. Conversely, if the specifications are not stringent, the manufacturer may be driven to choose the most economical strategy.

The first aim of an ISM is to enable the analysis and positioning of the inspection strategies implemented by a manufacturing company. Indeed, according to a cost-benefit logic, the combined use of the inspection indicators and their uncertainty allows the positioning of alternative inspection strategies into the map and, consequently, designers are guided in choosing the most appropriate one. ISM may also be adopted to compare more alternative inspection strategies, such as partial inspections in selected workstations, or strategies in which current control activities are modified or improved. Apart from being an analysis tool, the ISM can also be used as a design tool. In other words, by setting an objective point on the map, it is possible to determine which conditions of effectiveness and cost may guarantee its achievement. Thus, ISM can represent a powerful and practical decision tool to assist the inspection designers in quality assessment and improvement. An example of the use of ISM for both functionalities is discussed in the next Sect. 4.

\section{Case study: wrapping machines assembly}

\subsection{Manufacturing process modelling}

The proposed modelling of the manufacturing process was applied to the assembly process of wrapping machines for the packaging of palletised loads. In this study, the rotating ring wrapping machine was considered, specifically a single part of this machine, namely the pre-stretching device, produced by the Italian company Tosa Group S.p.A. (see Fig. 4). This device is common to all rotating ring wrapping machines, although each machine is customised and differs from the others for some details. In a typical year, 
Table 2 Variables related to the inspection strategy IS- 0 of the pre-stretching device

\begin{tabular}{|c|c|c|c|c|c|c|}
\hline $\begin{array}{l}\text { No. worksta- } \\
\text { tion }\end{array}$ & $\alpha_{i}[\%]$ & $\beta_{i}[\%]$ & $c_{i}[€]$ & $N R C_{i}[€]$ & $U R C_{i}[€]$ & $N D C_{i}[€]$ \\
\hline 1 & 0.5 & 0.8 & 0.12 & 0.37 & 0.37 & 1584.00 \\
\hline 2 & 0.5 & 0.8 & 0.32 & 0.73 & 0.73 & 1592.00 \\
\hline 3 & 0.3 & 0.5 & 0.25 & 0.37 & 0.37 & 87.00 \\
\hline 4 & 0.2 & 0.5 & 0.76 & 0.86 & 0.86 & 569.00 \\
\hline 5 & 0.4 & 0.8 & 0.56 & 2.02 & 2.02 & 483.00 \\
\hline 6 & 0.4 & 0.8 & 0.45 & 2.20 & 2.20 & 273.00 \\
\hline 7 & 0.1 & 0.1 & 0.14 & 0.18 & 0.18 & 11.00 \\
\hline 8 & 0.3 & 1.0 & 0.04 & 0.75 & 0.75 & 31.00 \\
\hline 9 & 0.4 & 0.6 & 0.08 & 0.09 & 0.09 & 47.00 \\
\hline 10 & 0.5 & 0.3 & 1.06 & 1.83 & 1.83 & 224.00 \\
\hline 11 & 0.2 & 0.2 & 0.29 & 0.15 & 0.15 & 11.67 \\
\hline 12 & 0.2 & 0.2 & 0.27 & 0.15 & 0.15 & 17.50 \\
\hline 13 & 0.3 & 0.3 & 0.26 & 0.05 & 0.05 & 8.75 \\
\hline 14 & 0.4 & 0.8 & 0.10 & 0.37 & 0.37 & 66.00 \\
\hline 15 & 0.3 & 0.3 & 0.31 & 0.12 & 0.12 & 5.83 \\
\hline 16 & 0.4 & 0.8 & 0.17 & 0.37 & 0.37 & 99.00 \\
\hline 17 & 0.2 & 0.2 & 0.13 & 0.02 & 0.02 & 6.00 \\
\hline 18 & 0.5 & 0.9 & 0.10 & 0.02 & 0.02 & 5.83 \\
\hline 19 & 0.2 & 0.2 & 0.37 & 0.05 & 0.05 & 5.83 \\
\hline 20 & 0.2 & 0.2 & 0.35 & 0.10 & 0.10 & 5.83 \\
\hline 21 & 0.5 & 0.7 & 0.32 & 0.18 & 0.18 & 5.83 \\
\hline 22 & 0.5 & 0.7 & 0.91 & 0.29 & 0.29 & 11.67 \\
\hline 23 & 0.2 & 0.2 & 0.04 & 0.07 & 0.07 & 5.83 \\
\hline 24 & 0.5 & 1.2 & 0.08 & 0.43 & 0.43 & 5.83 \\
\hline 25 & 0.5 & 1.2 & 0.12 & 0.43 & 0.43 & 5.83 \\
\hline 26 & 0.3 & 0.3 & 0.29 & 0.56 & 0.56 & 25.00 \\
\hline 27 & 0.2 & 0.2 & 0.34 & 0.09 & 0.09 & 5.83 \\
\hline 28 & 0.8 & 1.2 & 0.26 & 0.31 & 0.31 & 106.00 \\
\hline 29 & 0.5 & 0.5 & 0.17 & 0.07 & 0.07 & 5.83 \\
\hline
\end{tabular}

about 50 pre-stretching devices are assembled on different wrapping machines (low-volume production). Such an electromechanical device is designed to pull/unroll, pre-stretch and place the plastic film and finally to carry out the necessary number of windings on the pallet. The pre-stretching device assembly can be decomposed into 29 workstations: in the first 9 workstations, the assembly is performed on the bench by the operator, while in the last 20 workstations the subassemblies are assembled on the frame plate. For a detailed process decomposition, see Table 1 and Fig. 4. As mentioned in Sect. 2.1, the defect prediction model suitable for wrapping machines, reported in Eq. (6), was derived in a previous study by the authors [44]. This model was obtained from experimental $D P U_{i}$ occurring under stable process conditions in each workstation (see Table 1), collected over the last five years by the company. From the predicted $D P U_{i}$ values, the probability of occurrence of defective-workstationoutputs in optimal operating conditions, $p_{i}$, may be obtained by Eq. (7). The resulting values are reported in Table 1 and will be used to evaluate the inspection strategy performances in the next Sect. 4.2.

\subsection{Inspection strategies positioning using the ISM}

The current inspection strategy carried out by the company requires each workstation to be checked through an inspection activity, needing specific equipment depending on the workstation-output (see Table 5). Each control is affected by inspection errors. The estimates of $\alpha_{i}$ and $\beta_{i}$ (see Table 2) were obtained by the inspectors basing on historical data and empirical values referring to the assembly of pre-stretching devices. The two inspection strategy indicators of effectiveness and total cost are evaluated for the current inspection strategy, denoted as IS-0. Table 2 also reports the cost values used for estimating inspection total cost. Precisely, the estimates of $c_{i}$ were calculated considering the time 
Table 3 Mean values and 95\% confidence intervals of inspection performance indicators $D_{t o t}$ and $C_{t o t}$ for inspection strategies IS-0, IS-1 and IS-2

\begin{tabular}{lrlrl}
\hline $\begin{array}{l}\text { Inspec- } \\
\text { tion } \\
\text { strategy }\end{array}$ & $D_{\text {tot }}\left(\times 10^{-3}\right)$ & $\begin{array}{l}95 \% \text { confidence } \\
\text { interval of } D_{\text {tot }} \\
\left(\times 10^{-3}\right)\end{array}$ & $C_{\text {tot }}[€]$ & $\begin{array}{l}95 \% \text { confidence } \\
\text { interval of } C_{\text {tot }} \\
{[€]}\end{array}$ \\
\hline IS-0 & 4.80 & $(3.45 ; 6.15)$ & 10.74 & $(9.95 ; 11.53)$ \\
IS-1 & 378.61 & $(217.32 ; 539.91)$ & 10.13 & $(7.43 ; 12.83)$ \\
IS-2 & 1.51 & $(0.64 ; 2.37)$ & 11.41 & $(11.08 ; 11.75)$ \\
\hline
\end{tabular}

required for the inspection activity and the labour cost of operators/inspectors. $N R C_{i}$ and $U R C_{i}$, considered identical as a first approximation, were estimated starting from the time required for identifying and repairing possible defects (necessary or unnecessary) and the respective labour cost. Finally, $N D C_{i}$ was estimated considering the after-sales repair costs, calculated as the time for the repairs/substitutions and the operator labour costs.

Moreover, the estimates of the inspection performances are complemented by an estimation of their uncertainty. To this aim, Table 6 reports the estimates of the variances of the probabilities and costs of the model. Specifically, the variance of probabilities $p_{i}$ is obtained by composing the uncertainties of the two regression models parameters shown in Eq. (6) by using the approach proposed in Verna et al. [51]. Besides, the variances of inspection errors $\left(\alpha_{i}\right.$ and $\left.\beta_{i}\right)$ and the costs $\left(c_{i}, N R C_{i}, U R C_{i}\right.$ and $\left.N D C_{i}\right)$ are estimated by the inspectors based on previous experience.

Table 3 shows the indicators of effectiveness $D_{t o t}$ and total cost $C_{t o t}$ calculated according to Eqs. (8) and (9) and variable estimates listed in Tables 1 and 2. Furthermore, the $95 \%$ confidence intervals of the indicator estimates are provided in Table 3, according to Eqs. (10) and (11) and variable uncertainties reported in Table 6 .

As can be observed in Table 3, the mean number of defective-workstation-outputs which are not detected by the adopted inspection strategy, is nearly 5 units, considering a production of one thousand pre-stretching devices. As mentioned before, being the production of such devices of only 50 units per year, the number of defective-workstation-outputs that are erroneously not identified by the inspection strategy may be considered very little, i.e. 5 every 20 years. Moreover, by separately comparing the $D_{i}$ values, the most critical workstations in terms of residual defectiveness may be identified. In particular, the workstations with the highest values of $D_{i}$ are the number 28,5 and 24 respectively. For these workstations, the producer could design and adopt more effective inspection activities (see next Sect. 4.3).

Regarding the economic perspective, considering that the total cost of the pre-stretching device, including labour costs and materials, amounts to $3000 €$, the cost of the current inspection strategy is less than $1 \%$. Even for this indicator, individual $C_{t o t, i}$ values can be compared with each other to identify the most expensive workstations (in this case, numbers 5, 10 and 22 respectively). Therefore, the inspection in the workstation 5 is not only the worst in terms of effectiveness, but it is also the most expensive for the company. It should be noted that such a workstation is also the one with the highest value of $p_{i}$. As a consequence, due to the high number of defects, the sum of the cost components related to the repair $\left(N R C_{i} \cdot p_{i} \cdot\left(1-\beta_{i}\right)\right)$ and to the defects remaining in the prestretching device $\left(N D C_{i} \cdot p_{i} \cdot \beta_{i}\right)$ are higher than those in the other workstations.

As shown in Fig. 5, for the pre-stretching device, the two thresholds imposed by the company designer are $D^{*}{ }_{t o t}=4.00 \cdot 10^{-3}$ and $C^{*}{ }_{t o t}=15 €$. IS-0 is represented in Fig. 5 as a region delimited by the confidence intervals of both indicators, while the central point of the region corresponds to their average value. It can be noted that IS-0 region belongs only for a small part to the acceptance region and the central point falls in the rejection region. Thus, being this strategy not acceptable by the producer, two alternative strategies are analysed: IS-1 (Inspection Strategy 1) and IS-2 (Inspection Strategy 2).

In IS-1, only the workstations whose cost of undetected defects $\left(N D C_{i}\right)$ is considered expensive by the manufacturer (more than $50 €$ ) are inspected. In detail, these are the workstations number 1-6, 10,14, 16 and 28, respectively. Control methods performed in such workstations are the same as those adopted in the current strategy IS- 0 , and described in Table 5. Accordingly, the inspection variables related to such workstations have the same values of those reported in Tables 1 and 2. For the other workstations that are not subject to inspection, the corresponding inspection variables are $\alpha_{i}=0, \beta_{i}=1, c_{i}=0$, $N R C_{i}=0$ and $U R C_{i}=0$. In addition, for all the workstations, the probability $p_{i}$ and the cost $N D C_{i}$ do not change compared to IS-0, being not affected by the inspection strategy adopted. Table 7 reports the complete list of variables for IS-1.

In IS-2, selected workstations that are critical in terms of defectiveness (shown in Table 8) are accurately inspected through dedicated equipment and carried out by appointed staff. As a result, the cost of inspection activity $c_{i}$ for such workstations slightly increases because of an increase of hourly cost of dedicated equipment-due to the fixed cost of purchasing/obtaining the dedicated equipment-and inspection time by approximately $40 \%$. On the other hand, inspection errors decrease by about $85 \%$ with compared to IS- 0 . The remaining workstations are inspected using the same control methods carried out in the current strategy IS- 0 and, therefore, the inspection variables for these workstations are set equal to the values of IS-0 shown in Tables 1 and 2. It should be noted that $p_{i}, N R C_{i}$, $U R C_{i}$ and $N D C_{i}$ remain unchanged from IS-0 for all the workstations, being irrespective of the strategy implemented. Table 8 provides the complete list of variables for the strategy IS-2. 

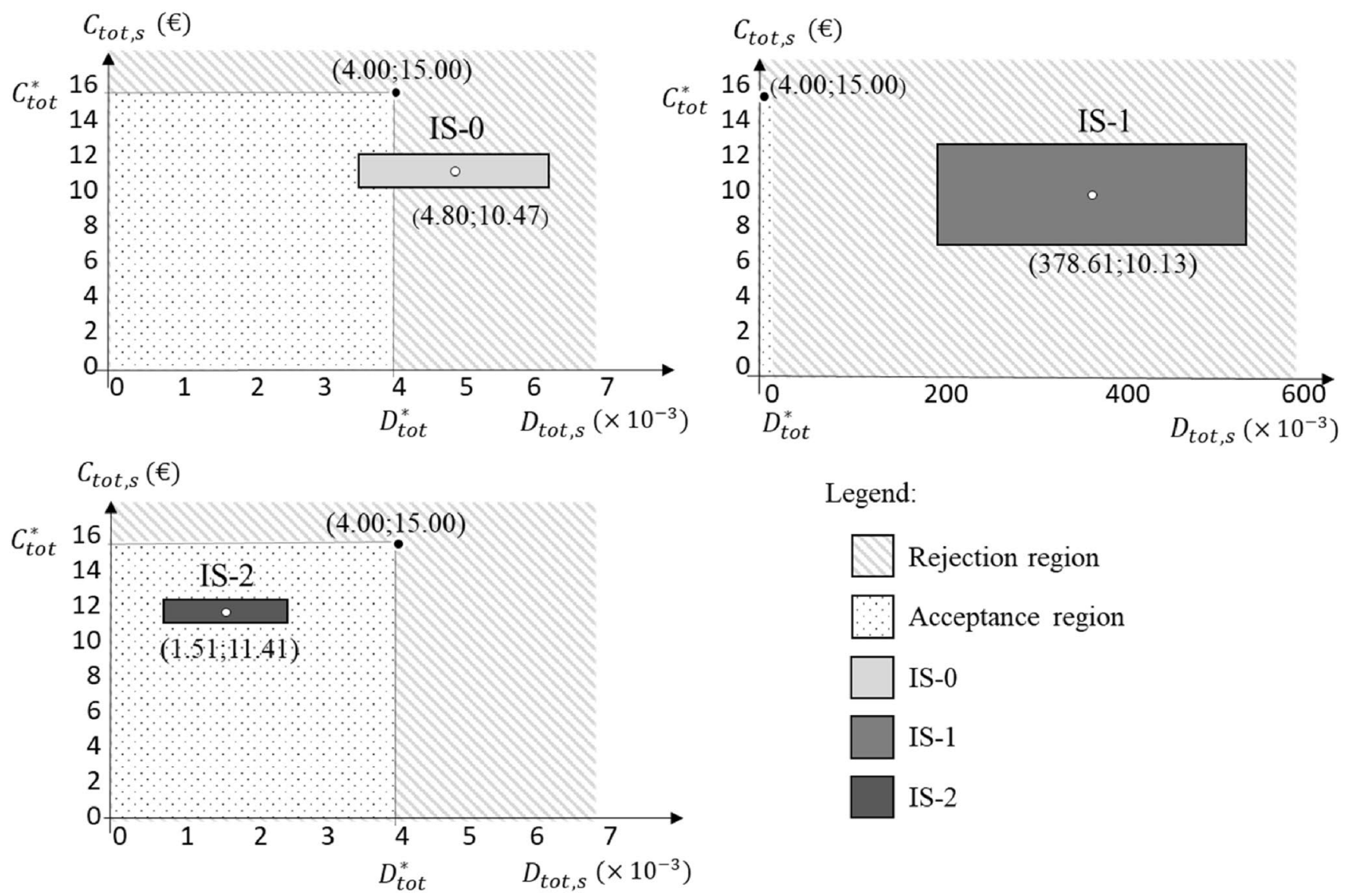

Legend:

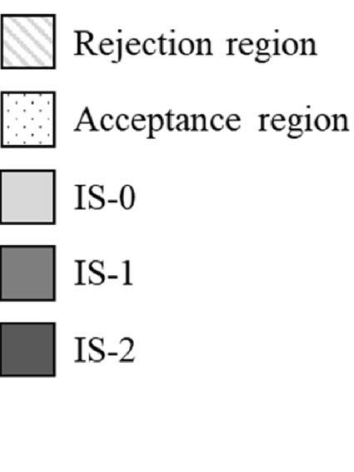

Fig. 5 Representation of the ISM for the inspection strategies IS-0, IS-1 and IS-2

Table 3 shows the mean values of the indicators $D_{\text {tot }}$ and $C_{t o t}$ of the two alternative inspection strategies IS-1 and IS-2 and their $95 \%$ confidence intervals.

\subsection{Comparison and analysis of alternative inspection strategies}

Given the results shown in Fig. 5, the strategy IS-1 is out of the acceptance region. The indicator $D_{t o t}$ is about two orders of magnitude higher than the threshold, although $C_{t o t}$ is in line with the manufacturer's requirements. Indeed, performing IS-1 leads to a significant increase in the indicator of effectiveness, caused by the non-inspection of selected workstations and, therefore, by leaving defects in the final pre-stretching device. However, the inspection total cost of such a strategy remains affordable and comparable with the cost of the other two strategies because the absence of inspection in the workstations with the lowest values of $N D C_{i}$ does not entail inspection and repair costs, but only costs of undetected defects, which remain minimal.
Regarding strategies IS-0 and IS-2, the comparison of the corresponding indicators is shown in the ISM illustrated in Fig. 6.

The strategy to be preferred is IS-2. It is the only strategy that allows for a residual defectiveness lower than the threshold $D^{*}{ }_{t o t}$ imposed by the producer. From an economic point of view, both strategies lead to comparable costs, although IS-2 is on average slightly more expensive than IS-0. Besides, as shown in Fig. 6, inspection indicators $D_{\text {tot }}$ and $C_{\text {tot }}$ obtained for IS-2 are affected by less uncertainty compared to those obtained for IS-0. Accordingly, the estimates of the two indicators are more accurate for IS- 2 than IS-0. Furthermore, it has to be highlighted that when no inspection is performed in all the workstations, the total cost will be $C_{\text {tot }}=\sum_{i=1}^{m} N D C_{i} \cdot p_{i}=202.40 €$ (see Eq. (9) in which $\alpha_{i}=0, \beta_{i}=1$ and $\left.c_{i}=N R C_{i}=U R C_{i}=0\right)$. In light of this, since in this case study the higher costs are those of undetected defective-workstation-outputs and not performing inspections leads to a very high cost, i.e., $202.40 €$, it is advisable choosing an inspection strategy that minimises 
Fig. 6 Comparison of the inspection strategies IS-0 and IS-2 using the ISM
Fig. 7 Representation in the ISM of the "target point" (IS-3) to be achieved starting from the condition IS- 0

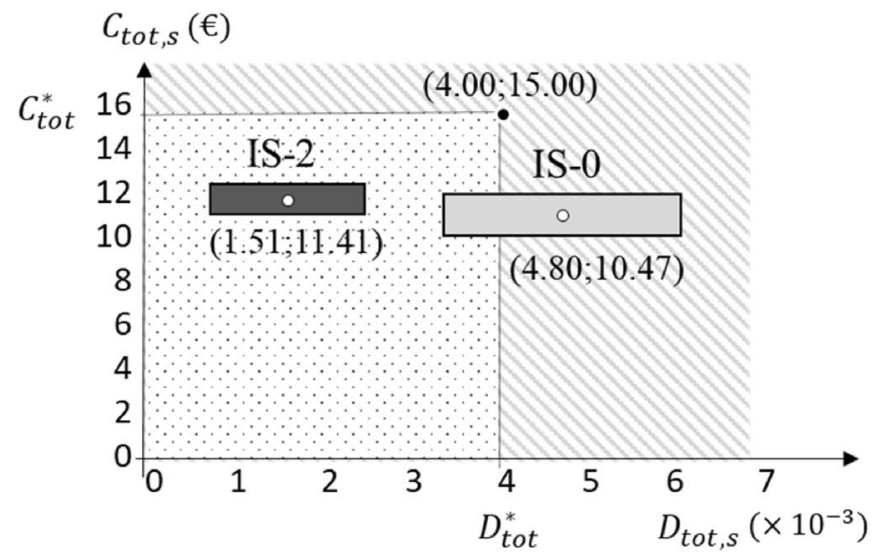

Legend:

Rejection region

Acceptance region

IS-0

IS-2

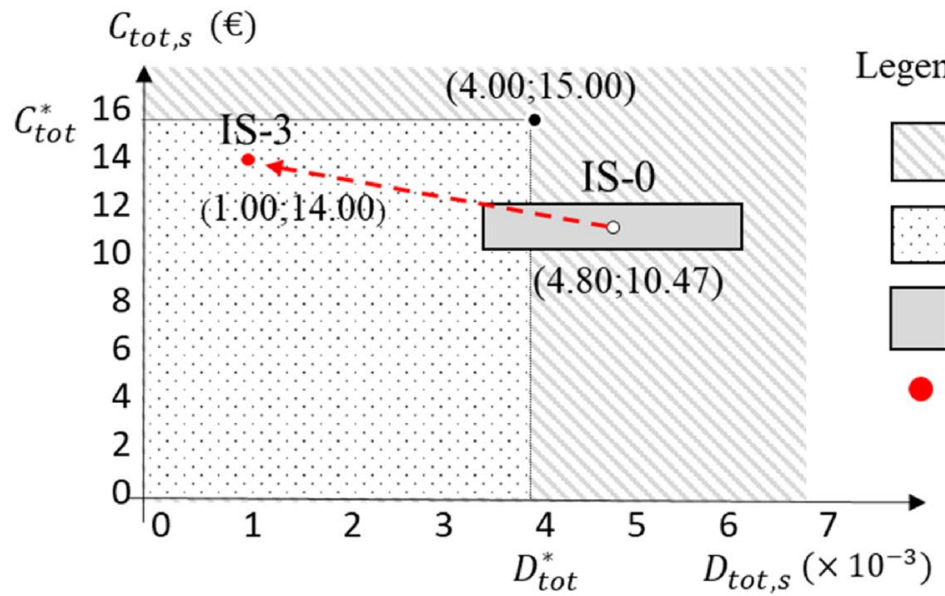

Rejection region

Acceptance region

IS-0

Target point (IS-3)

such a cost component through high-performance inspections, without, however, significantly increasing the costs of inspection activities, as in the case of the strategy IS-2.

\subsection{ISM for designing inspections}

ISM can also be used in a reverse way to the approach discussed in Sect. 4.3. In other words, when the designer wants to achieve effectiveness and cost objective, represented by a "target point" on ISM, this tool can guide designer choices. Indeed, when the target values of indicators $D_{t o t}$ and $C_{t o t}$ are known, the conditions for their implementation can be determined. For instance, suppose that the wrapping machines company aims to set as target values of the indicators $D_{\text {tot }}$ and $C_{t o t}$ respectively $1.00 \cdot 10^{-3}$ and $14 €$ (IS-3). This situation is represented in Fig. 7. In order to reach the target point, since probabilities $p_{i}$ are physiological characteristics of the production process, and being $N R C_{i}, U R C_{i}$ and $N D C_{i}$ costs irrespective of the strategy adopted, the only variables to be addressed are inspection errors $\alpha_{i}$ and $\beta_{i}$ and the costs of inspection activities $c_{i}$. A possible strategy involves reducing inspection errors by $80 \%$ compared to the strategy IS-0 by improving quality controls in all the workstation (e.g. using dedicated equipment and training inspectors). As a consequence, it is assumed that inspection costs will increase by $50 \%$ (see Table 4 ). In this case, the resulting indicators $D_{\text {tot }}$ and $C_{\text {tot }}$ becomes respectively $0.96 \cdot 10^{-3}$ and $13.76 €$. It should be noted that, although the $\operatorname{cost} c_{i}$ is increased for all the workstations by $50 \%$, the strategy total cost is approximately $30 \%$ higher than that of IS- 0 owing to the $80 \%$ reduction in both the cost of undetected defects and unnecessary repairs.

\section{Conclusions}

The design of effective and cost-efficient quality-inspection strategies in manufacturing processes may be extremely challenging, mainly for low-volume productions due to the non-applicability of traditional statistical techniques. 
Table 4 Variables $\alpha_{i}, \beta_{i}$ and $c_{i}$ related to the inspection strategy IS-3 of the pre-stretching device

\begin{tabular}{|c|c|c|c|}
\hline $\begin{array}{l}\text { No. } \\
\text { worksta- } \\
\text { tion }\end{array}$ & $\alpha_{i}[\%]$ & $\beta_{i}[\%]$ & $c_{i}[€]$ \\
\hline 1 & 0.10 & 0.16 & 0.18 \\
\hline 2 & 0.10 & 0.16 & 0.48 \\
\hline 3 & 0.06 & 0.10 & 0.38 \\
\hline 4 & 0.04 & 0.10 & 1.15 \\
\hline 5 & 0.08 & 0.16 & 0.84 \\
\hline 6 & 0.08 & 0.16 & 0.67 \\
\hline 7 & 0.02 & 0.02 & 0.21 \\
\hline 8 & 0.06 & 0.20 & 0.06 \\
\hline 9 & 0.08 & 0.12 & 0.12 \\
\hline 10 & 0.10 & 0.06 & 1.60 \\
\hline 11 & 0.04 & 0.04 & 0.43 \\
\hline 12 & 0.04 & 0.04 & 0.40 \\
\hline 13 & 0.06 & 0.06 & 0.39 \\
\hline 14 & 0.08 & 0.16 & 0.15 \\
\hline 15 & 0.06 & 0.06 & 0.46 \\
\hline 16 & 0.08 & 0.16 & 0.25 \\
\hline 17 & 0.04 & 0.04 & 0.20 \\
\hline 18 & 0.10 & 0.18 & 0.16 \\
\hline 19 & 0.04 & 0.04 & 0.55 \\
\hline 20 & 0.04 & 0.04 & 0.52 \\
\hline 21 & 0.10 & 0.14 & 0.48 \\
\hline 22 & 0.10 & 0.14 & 1.37 \\
\hline 23 & 0.04 & 0.04 & 0.06 \\
\hline 24 & 0.10 & 0.24 & 0.12 \\
\hline 25 & 0.10 & 0.24 & 0.18 \\
\hline 26 & 0.06 & 0.06 & 0.44 \\
\hline 27 & 0.04 & 0.04 & 0.51 \\
\hline 28 & 0.16 & 0.24 & 0.39 \\
\hline 29 & 0.10 & 0.10 & 0.25 \\
\hline
\end{tabular}

Inspection designer may adopt a variety of inspection strategies indicating the workstations to inspect and the inspection method to be used. Recent studies proposed the use of defect prediction models to plan in-process inspections in early design phases. Nonetheless, a decision support tool for designers enabling the assessment of the adequacy of alternative inspection strategies has not yet been addressed. Considering this literature gap, this paper proposes a strategic tool, named Inspection Strategy Map (ISM), able to guide inspection designers in the inspection planning process from the early design phases. The proposed tool relies on defect generation models and uses a pair of practical indicators depicting the effectiveness and total cost of an inspection strategy to map the company's scenario. ISM can support inspection designers for:

- enabling positioning assessment and benchmarking of different inspection strategies;

- driving designer choices to achieve desired specification targets.

The approach is described through a practical case study concerning the assembly of wrapping machines (low-volume production). The current inspection strategy, IS-0, is compared with other two potential alternatives, IS-1 and IS-2. In the former, only selected workstations are inspected using the same controls currently adopted. In the latter, all the workstations are inspected, but in some of them the controls are enhanced by dedicated equipment and staff. The use of the ISM allowed to identify the best strategy for the company, i.e. IS-2, because it satisfies both effectiveness and cost constraints. In addition, the ISM is used to guide inspectors by showing how to achieve the target strategy (i.e., IS-3) from the current condition IS-0. In detail, the most appropriate solution is to improve quality controls in all the workstations, e.g., by training inspectors, leading to a significant increase in inspection effectiveness with a slight increase in costs. Regarding the future, authors are planning to extend the use of ISMs to online monitoring of inspection activities.

\section{Appendices}

See Tables 5, 6, 7, 8 . 
Table 5 Current inspection strategy of the pre-stretching device: description of the controls performed in the workstations and the equipment used

\begin{tabular}{|c|c|c|c|}
\hline $\begin{array}{l}\text { No. } \\
\text { work- } \\
\text { station }\end{array}$ & Control type & Control description & Equipment \\
\hline 1 & Visual and manual & $\begin{array}{l}\text { Cleaning of motor shaft } 1 \text {, alignment of groups pulley-motor shaft } 1 \text { and } \\
\text { clamping ring-motor shaft } 1\end{array}$ & Hands \\
\hline 2 & Visual, manual and dimensional & $\begin{array}{l}\text { Cleaning of motor shaft 2, correct dimensions of the groups shrink disk- } \\
\text { crankshaft } 2 \text { and pulley-crankshaft } 2\end{array}$ & Hands, caliper, bench vice \\
\hline 3 & Visual and manual & $\begin{array}{l}\text { Surface cleaning of motor support plate } 2 \text { and correct assembly of the } \\
\text { upper and lower plate }\end{array}$ & Hands \\
\hline 4 & Visual, manual and mechanical & $\begin{array}{l}\text { Presence of all the components for the spindle subassembly and spindle } \\
\text { spring operation }\end{array}$ & Hands \\
\hline 5 & Visual, manual and mechanical & $\begin{array}{l}\text { Cleaning of the wheeled roller shaft and correct rotation of the wheeled } \\
\text { roller assembly }\end{array}$ & Hands \\
\hline 6 & Visual, manual and mechanical & Cleaning of idle rolls shaft and correct rotation of idle rollers assembly & Hands \\
\hline 7 & Visual and geometric & $\begin{array}{l}\text { Correct positioning of the rubber pad assembly } 1 \text { and } 2 \text { and hexagonal } \\
\text { support of the rubber pad assembly } 1 \text { and } 2\end{array}$ & Hands \\
\hline 8 & Visual and mechanical & $\begin{array}{l}\text { Alignment of the belt tensioning device group and correct rotation of the } \\
\text { belt tensioning device roller }\end{array}$ & Hands \\
\hline 9 & Visual and mechanical & $\begin{array}{l}\text { Penetration of the protective on the surface of the driven wheels and } \\
\text { correct positioning of the clamping rings in the transmission-driven } \\
\text { wheels }\end{array}$ & Hands \\
\hline 10 & Visual & Aesthetic appearance of the surface plate of the pre-stretch frame & Hands \\
\hline 11 & Mechanical and geometric & $\begin{array}{l}\text { Correct rotation of the rubber rolls and alignment of the rubber rollers } \\
\text { on the pre-stretch frame plate }\end{array}$ & Hands \\
\hline 12 & Mechanical and geometric & $\begin{array}{l}\text { Correct idle roller rotation and alignment of the idle rollers on the pre- } \\
\text { stretch frame plate }\end{array}$ & Hands \\
\hline 13 & Mechanical & Correct tightening of the motor bolts 1 on the frame plate & Hands \\
\hline 14 & Visual & Correct positioning of the components & Hands \\
\hline 15 & Visual and mechanical & Correct tightening of motor bolts 2 on the frame plate & Hands \\
\hline 16 & Visual & Correct positioning of components & Hands \\
\hline 17 & Visual & Correct positioning of the motor casing 1 & Hands \\
\hline 18 & Mechanical and geometric & $\begin{array}{l}\text { Correct alignment of the belt tensioner assembly and rotation of the belt } \\
\text { tensioning device roller }\end{array}$ & Hands \\
\hline 19 & Mechanical and geometric & Movement of the motor drive belt 1 & Hands \\
\hline 20 & Mechanical and geometric & Movement of the motor drive belt 2 & Hands \\
\hline 21 & Visual and mechanical & $\begin{array}{l}\text { Check the number of screws removed from the component and correct } \\
\text { operation of the internal spindle spring }\end{array}$ & Hands \\
\hline 22 & Mechanical and geometric & $\begin{array}{l}\text { Correct spindle rotation on the pre-stretch frame plate and alignment of } \\
\text { the spindle assembly on the pre-stretch frame plate }\end{array}$ & Hands \\
\hline 23 & Geometric & Correct alignment of the pads on the pre-stretch frame plate & Hands \\
\hline 24 & Manual and mechanical & $\begin{array}{l}\text { Correct operation of the motor } 1 \text {, final check of the motor } 1 \text { drive belt } \\
\text { tension and final alignment check of the motor } 1 \text { transmission assem- } \\
\text { bly }\end{array}$ & Hands \\
\hline 25 & Manual and mechanical & $\begin{array}{l}\text { Correct operation of the motor } 2 \text {, final check of the motor } 2 \text { drive belt } \\
\text { tension and final alignment check of the motor } 2 \text { transmission assem- } \\
\text { bly }\end{array}$ & Hands \\
\hline 26 & Visual and mechanical & Alignment and correct movement of spindle release lever assembly & Hands \\
\hline 27 & Mechanical and geometric & $\begin{array}{l}\text { Correct movement and alignment of the spindle release lever on the pre- } \\
\text { stretch frame plate }\end{array}$ & Hands \\
\hline 28 & $\begin{array}{l}\text { Visual, geometric, mechanical } \\
\text { and dimensional }\end{array}$ & $\begin{array}{l}\text { Correct rotation of the compensation arm roller and alignment of the } \\
\text { cam system }\end{array}$ & $\begin{array}{l}\text { Hands, caliper, metallic } \\
\text { ruler, Gauge block }\end{array}$ \\
\hline 29 & Visual and mechanical & $\begin{array}{l}\text { Correct movement of the compensation arm assembly on the pre-stretch } \\
\text { frame plate and correct rotation of the compensation arm roller }\end{array}$ & Hands \\
\hline
\end{tabular}


Table 6 Variances of the variables related to the process and the current inspection strategy of the pre-stretching device (IS-0)

\begin{tabular}{|c|c|c|c|c|c|c|c|}
\hline $\begin{array}{l}\text { No. } \\
\text { worksta- } \\
\text { tion }\end{array}$ & $\begin{array}{l}\operatorname{VAR}\left(\boldsymbol{p}_{i}\right) \\
\left(\times 10^{-4}\right)\end{array}$ & $\begin{array}{l}\operatorname{VAR}\left(\alpha_{i}\right) \\
\left(\times 10^{-7}\right)\end{array}$ & $\begin{array}{l}V A R\left(\beta_{i}\right) \\
\left(\times 10^{-7}\right)\end{array}$ & $\begin{array}{l}\operatorname{VAR}\left(c_{i}\right) \\
\left(\times 10^{-4}\right)\left[€^{2}\right]\end{array}$ & $\begin{array}{l}\operatorname{VAR}\left(N R C_{i}\right) \\
\left(\times 10^{-4}\right)\left[€^{2}\right]\end{array}$ & $\begin{array}{l}\operatorname{VAR}\left(U R C_{i}\right) \\
\left(\times 10^{-4}\right)\left[€^{2}\right]\end{array}$ & $\begin{array}{l}\operatorname{VAR}\left(N D C_{i}\right) \\
\left(\times 10^{1}\right)\left[€^{2}\right]\end{array}$ \\
\hline 1 & 3.30 & 0.63 & 1.60 & 0.36 & 3.42 & 3.42 & 2.50 \\
\hline 2 & 3.29 & 0.63 & 1.60 & 2.56 & 13.32 & 13.32 & 2.50 \\
\hline 3 & 3.35 & 0.23 & 0.63 & 1.56 & 3.42 & 3.42 & 1.89 \\
\hline 4 & 3.40 & 0.10 & 0.63 & 14.44 & 18.49 & 18.49 & 2.50 \\
\hline 5 & 3.38 & 0.40 & 1.60 & 7.84 & 102.01 & 102.01 & 2.50 \\
\hline 6 & 3.27 & 0.40 & 1.60 & 5.06 & 121.00 & 121.00 & 2.50 \\
\hline 7 & 3.40 & 0.03 & 0.03 & 0.49 & 0.81 & 0.81 & 0.03 \\
\hline 8 & 3.39 & 0.23 & 2.50 & 0.04 & 14.06 & 14.06 & 0.24 \\
\hline 9 & 3.33 & 0.40 & 0.90 & 0.16 & 0.20 & 0.20 & 0.55 \\
\hline 10 & 3.43 & 0.63 & 0.23 & 28.09 & 83.72 & 83.72 & 2.50 \\
\hline 11 & 3.34 & 0.10 & 0.10 & 2.10 & 0.56 & 0.56 & 0.03 \\
\hline 12 & 3.30 & 0.10 & 0.10 & 1.82 & 0.56 & 0.56 & 0.08 \\
\hline 13 & 3.42 & 0.23 & 0.23 & 1.69 & 0.06 & 0.06 & 0.02 \\
\hline 14 & 3.34 & 0.40 & 1.60 & 0.25 & 3.42 & 3.42 & 1.09 \\
\hline 15 & 3.33 & 0.23 & 0.23 & 2.40 & 0.36 & 0.36 & 0.01 \\
\hline 16 & 3.48 & 0.40 & 1.60 & 0.72 & 3.42 & 3.42 & 2.45 \\
\hline 17 & 3.34 & 0.10 & 0.10 & 0.42 & 0.01 & 0.01 & 0.01 \\
\hline 18 & 3.48 & 0.63 & 2.03 & 0.25 & 0.01 & 0.01 & 0.01 \\
\hline 19 & 3.42 & 0.10 & 0.10 & 3.42 & 0.06 & 0.06 & 0.01 \\
\hline 20 & 3.41 & 0.10 & 0.10 & 3.06 & 0.25 & 0.25 & 0.01 \\
\hline 21 & 3.36 & 0.63 & 1.23 & 2.56 & 0.81 & 0.81 & 0.01 \\
\hline 22 & 3.49 & 0.63 & 1.23 & 20.70 & 2.10 & 2.10 & 0.03 \\
\hline 23 & 3.36 & 0.10 & 0.10 & 0.04 & 0.12 & 0.12 & 0.01 \\
\hline 24 & 3.55 & 0.63 & 3.60 & 0.16 & 4.62 & 4.62 & 0.01 \\
\hline 25 & 3.55 & 0.63 & 3.60 & 0.36 & 4.62 & 4.62 & 0.01 \\
\hline 26 & 3.34 & 0.23 & 0.23 & 2.10 & 7.84 & 7.84 & 0.16 \\
\hline 27 & 3.46 & 0.10 & 0.10 & 2.89 & 0.20 & 0.20 & 0.01 \\
\hline 28 & 4.48 & 1.60 & 3.60 & 1.69 & 2.40 & 2.40 & 2.50 \\
\hline 29 & 3.42 & 0.63 & 0.63 & 0.72 & 0.12 & 0.12 & 0.01 \\
\hline
\end{tabular}


Table 7 Variables related to the inspection strategy IS-1 of the pre-stretching device

\begin{tabular}{|c|c|c|c|c|c|c|}
\hline $\begin{array}{l}\text { No. worksta- } \\
\text { tion }\end{array}$ & $\alpha_{i}[\%]$ & $\beta_{i}[\%]$ & $c_{i}[€]$ & $N R C_{i}[€]$ & $U R C_{i}[€]$ & $N D C_{i}[€]$ \\
\hline 1 & 0.5 & 0.8 & 0.12 & 0.37 & 0.37 & 1584.00 \\
\hline 2 & 0.5 & 0.8 & 0.32 & 0.73 & 0.73 & 1592.00 \\
\hline 3 & 0.3 & 0.5 & 0.25 & 0.37 & 0.37 & 87.00 \\
\hline 4 & 0.2 & 0.5 & 0.76 & 0.86 & 0.86 & 569.00 \\
\hline 5 & 0.4 & 0.8 & 0.56 & 2.02 & 2.02 & 483.00 \\
\hline 6 & 0.4 & 0.8 & 0.45 & 2.20 & 2.20 & 273.00 \\
\hline 7 & 0.0 & 100.0 & 0.00 & 0.00 & 0.00 & 11.00 \\
\hline 8 & 0.0 & 100.0 & 0.00 & 0.00 & 0.00 & 31.00 \\
\hline 9 & 0.0 & 100.0 & 0.00 & 0.00 & 0.00 & 47.00 \\
\hline 10 & 0.5 & 0.3 & 1.06 & 1.83 & 1.83 & 224.00 \\
\hline 11 & 0.0 & 100.0 & 0.00 & 0.00 & 0.00 & 11.67 \\
\hline 12 & 0.0 & 100.0 & 0.00 & 0.00 & 0.00 & 17.50 \\
\hline 13 & 0.0 & 100.0 & 0.00 & 0.00 & 0.00 & 8.75 \\
\hline 14 & 0.4 & 0.8 & 0.10 & 0.37 & 0.37 & 66.00 \\
\hline 15 & 0.0 & 100.0 & 0.00 & 0.00 & 0.00 & 5.83 \\
\hline 16 & 0.4 & 0.8 & 0.17 & 0.37 & 0.37 & 99.00 \\
\hline 17 & 0.0 & 100.0 & 0.00 & 0.00 & 0.00 & 6.00 \\
\hline 18 & 0.0 & 100.0 & 0.00 & 0.00 & 0.00 & 5.83 \\
\hline 19 & 0.0 & 100.0 & 0.00 & 0.00 & 0.00 & 5.83 \\
\hline 20 & 0.0 & 100.0 & 0.00 & 0.00 & 0.00 & 5.83 \\
\hline 21 & 0.0 & 100.0 & 0.00 & 0.00 & 0.00 & 5.83 \\
\hline 22 & 0.0 & 100.0 & 0.00 & 0.00 & 0.00 & 11.67 \\
\hline 23 & 0.0 & 100.0 & 0.00 & 0.00 & 0.00 & 5.83 \\
\hline 24 & 0.0 & 100.0 & 0.00 & 0.00 & 0.00 & 5.83 \\
\hline 25 & 0.0 & 100.0 & 0.00 & 0.00 & 0.00 & 5.83 \\
\hline 26 & 0.0 & 100.0 & 0.00 & 0.00 & 0.00 & 25.00 \\
\hline 27 & 0.0 & 100.0 & 0.00 & 0.00 & 0.00 & 5.83 \\
\hline 28 & 0.8 & 1.2 & 0.26 & 0.31 & 0.31 & 106.00 \\
\hline 29 & 0.0 & 100.0 & 0.00 & 0.00 & 0.00 & 5.83 \\
\hline
\end{tabular}

Workstations subject to inspection are written in bold type 
Table 8 Variables related to the inspection strategy IS-2 of the pre-stretching device

\begin{tabular}{|c|c|c|c|c|c|c|}
\hline $\begin{array}{l}\text { No. worksta- } \\
\text { tion }\end{array}$ & $\alpha_{i}[\%]$ & $\beta_{i}[\%]$ & $c_{i}[€]$ & $N R C_{i}[€]$ & $U R C_{i}[€]$ & $N D C_{i}[€]$ \\
\hline 1 & 0.07 & 0.10 & 0.17 & 0.37 & 0.37 & 1584.00 \\
\hline 2 & 0.07 & 0.10 & 0.43 & 0.73 & 0.73 & 1592.00 \\
\hline 3 & 0.04 & 0.07 & 0.34 & 0.37 & 0.37 & 87.00 \\
\hline 4 & 0.03 & 0.07 & 1.03 & 0.86 & 0.86 & 569.00 \\
\hline 5 & 0.04 & 0.08 & 0.76 & 2.02 & 2.02 & 483.00 \\
\hline 6 & 0.04 & 0.08 & 0.60 & 2.20 & 2.20 & 273.00 \\
\hline 7 & 0.10 & 0.10 & 0.14 & 0.18 & 0.18 & 11.00 \\
\hline 8 & 0.30 & 1.00 & 0.04 & 0.75 & 0.75 & 31.00 \\
\hline 9 & 0.40 & 0.60 & 0.08 & 0.09 & 0.09 & 47.00 \\
\hline 10 & 0.50 & 0.30 & 1.06 & 1.83 & 1.83 & 224.00 \\
\hline 11 & 0.03 & 0.03 & 0.39 & 0.15 & 0.15 & 11.67 \\
\hline 12 & 0.20 & 0.20 & 0.27 & 0.15 & 0.15 & 17.50 \\
\hline 13 & 0.04 & 0.04 & 0.35 & 0.05 & 0.05 & 8.75 \\
\hline 14 & 0.05 & 0.10 & 0.13 & 0.37 & 0.37 & 66.00 \\
\hline 15 & 0.04 & 0.04 & 0.41 & 0.12 & 0.12 & 5.83 \\
\hline 16 & 0.40 & 0.80 & 0.17 & 0.37 & 0.37 & 99.00 \\
\hline 17 & 0.20 & 0.20 & 0.13 & 0.02 & 0.02 & 6.00 \\
\hline 18 & 0.07 & 0.12 & 0.14 & 0.02 & 0.02 & 5.83 \\
\hline 19 & 0.03 & 0.03 & 0.50 & 0.05 & 0.05 & 5.83 \\
\hline 20 & 0.03 & 0.03 & 0.47 & 0.10 & 0.10 & 5.83 \\
\hline 21 & 0.05 & 0.07 & 0.43 & 0.18 & 0.18 & 5.83 \\
\hline 22 & 0.07 & 0.09 & 1.23 & 0.29 & 0.29 & 11.67 \\
\hline 23 & 0.20 & 0.20 & 0.04 & 0.07 & 0.07 & 5.83 \\
\hline 24 & 0.50 & 1.20 & 0.08 & 0.43 & 0.43 & 5.83 \\
\hline 25 & 0.50 & 1.20 & 0.12 & 0.43 & 0.43 & 5.83 \\
\hline 26 & 0.30 & 0.30 & 0.29 & 0.56 & 0.56 & 25.00 \\
\hline 27 & 0.20 & 0.20 & 0.34 & 0.09 & 0.09 & 5.83 \\
\hline 28 & 0.08 & 0.12 & 0.35 & 0.31 & 0.31 & 106.00 \\
\hline 29 & 0.07 & 0.07 & 0.22 & 0.07 & 0.07 & 5.83 \\
\hline
\end{tabular}

Workstations accurately inspected by appointed staff through dedicated equipment are written in bold type
Acknowledgements The authors gratefully acknowledge Tosa Group S.p.A. (Italy) for the fruitful collaboration.

Funding Open access funding provided by Politecnico di Torino within the CRUI-CARE Agreement. This work has been partially supported by the "Italian Ministry of Education, University and Research", Award "TESUN-83486178370409 finanziamento dipartimenti di eccellenza CAP. 1694 TIT. 232 ART. 6".

Open Access This article is licensed under a Creative Commons Attribution 4.0 International License, which permits use, sharing, adaptation, distribution and reproduction in any medium or format, as long as you give appropriate credit to the original author(s) and the source, provide a link to the Creative Commons licence, and indicate if changes were made. The images or other third party material in this article are included in the article's Creative Commons licence, unless indicated otherwise in a credit line to the material. If material is not included in the article's Creative Commons licence and your intended use is not permitted by statutory regulation or exceeds the permitted use, you will need to obtain permission directly from the copyright holder. To view a copy of this licence, visit http://creativecommons.org/licenses/by/4.0/.

\section{References}

1. Schmidt C, Hocke T, Denkena B (2019) Deep learning-based classification of production defects in automated-fiber-placement processes. Prod Eng 13:501-509

2. Stellin T, van Tijum R, Engel U (2016) Modelling and experimental study of a microforging process from metal strip for the reduction of defects in mass production. Prod Eng 10:103-112

3. Galetto M, Verna E, Genta G (2021) Effect of process parameters on parts quality and process efficiency of fused deposition modeling. Comput Ind Eng 156:107238. https://doi.org/10.1016/j.cie. 2021.107238

4. Franceschini F, Galetto M, Genta G, Maisano DA (2018) Selection of quality-inspection procedures for short-run productions. Int J Adv Manuf Technol 99:2537-2547

5. Savio E, De Chiffre L, Carmignato S, Meinertz J (2016) Economic benefits of metrology in manufacturing. CIRP Ann Manuf Technol 65:495-498

6. Tirkel I, Rabinowitz G (2014) Modeling cost benefit analysis of inspection in a production line. Int J Prod Econ 147:38-45 
7. Verna E, Genta G, Galetto M, Franceschini F (2020) Planning offline inspection strategies in low-volume manufacturing processes. Qual Eng 32:705-720

8. Galetto M, Genta G, Maculotti G, Verna E (2020) Defect probability estimation for hardness-optimised parts by selective laser melting. Int J Precis Eng Manuf 21:1739-1753

9. Genta G, Galetto M, Franceschini F (2020) Inspection procedures in manufacturing processes: recent studies and research perspectives. Int J Prod Res 58:4767-4788

10. Tzimerman A, Herer YT (2009) Off-line inspections under inspection errors. IIE Trans 41:626-641

11. Tirkel I, Rabinowitz G, Price D, Sutherland D (2016) Wafer fabrication yield learning and cost analysis based on in-line inspection. Int J Prod Res 54:3578-3590

12. Azadeh A, Sangari MS, Sangari E, Fatehi S (2015) A particle swarm algorithm for optimising inspection policies in serial multistage production processes with uncertain inspection costs. Int J Comput Integr Manuf 28:766-780

13. Wang W (2009) An inspection model for a process with two types of inspections and repairs. Reliab Eng Syst Saf 94:526-533

14. Kang CW, Ramzan MB, Sarkar B, Imran M (2018) Effect of inspection performance in smart manufacturing system based on human quality control system. Int J Adv Manuf Technol 94:4351-4364

15. Neu H, Hanne T, Münch J, et al (2002) Simulation-based risk reduction for planning inspections. In: International Conference on Product Focused Software Process Improvement PROFES 2002. Springer, 9-11 December, Rovaniemi, Finland, pp 78-93

16. Neu H, Hanne T, Münch J, et al (2003) Creating a code inspection model for simulation-based decision support. In: 4th International Workshop on Software Process Simulation and Modeling ProSim'03. May 3-4, Portland State University, Oregon, USA, pp 1-10

17. Münch J, Berlage T, Hanne T, et al (2002) Simulation-based evaluation and improvement of software development processes. SEV Prog Rep No 1, Tech Rep No 04802/E

18. Savio E (2012) A methodology for the quantification of valueadding by manufacturing metrology. CIRP Ann Technol 61:503-506

19. Hanne T, Nickel S (2005) A multiobjective evolutionary algorithm for scheduling and inspection planning in software development projects. Eur J Oper Res 167:663-678

20. Shiau Y-R (2003) Inspection allocation planning for a multiple quality characteristic advanced manufacturing system. Int J Adv Manuf Technol 21:494-500

21. Mohammadi M, Siadat A, Dantan J-Y, Tavakkoli-Moghaddam R (2015) Mathematical modelling of a robust inspection process plan: Taguchi and Monte Carlo methods. Int J Prod Res 53:2202-2224

22. Burggräf P, Wagner J, Lück K, Adlon T (2017) Cost-benefit analysis for disruption prevention in low-volume assembly. Prod Eng 11:331-342

23. Trovato E, Castagliola P, Celano G, Fichera S (2010) Economic design of inspection strategies to monitor dispersion in short production runs. Comput Ind Eng 59:887-897

24. Celano G, Castagliola P, Trovato E, Fichera S (2011) Shewhart and EWMA t control charts for short production runs. Qual Reliab Eng Int 27:313-326

25. Marques PA, Cardeira CB, Paranhos P et al (2015) Selection of the most suitable statistical process control approach for short production runs: a decision-model. Int J Inf Educ Technol 5:303

26. Del Castillo E, Grayson JM, Montgomery DC, Runger GC (1996) A review of statistical process control techniques for short run manufacturing systems. Commun Stat Methods 25:2723-2737
27. Pillet M (1996) A specific SPC chart for small-batch control. Qual Eng 8:581-586

28. Khoo MBC, Quah SH (2002) Proposed short runs multivariate control charts for the process mean. Qual Eng 14:603-621

29. Genta G, Galetto M, Franceschini F (2018) Product complexity and design of inspection strategies for assembly manufacturing processes. Int J Prod Res 56:4056-4066

30. Shibata H (2002) Global assembly quality methodology: a new methodology for evaluating assembly complexities in globally distributed manufacturing. PhD dissertation, Mechanical Engineering Department, Stanford University

31. Su Q, Liu L, Whitney DE (2010) A systematic study of the prediction model for operator-induced assembly defects based on assembly complexity factors. IEEE Trans Syst Man Cybern Part A Syst Hum 40:107-120

32. Hinckley CM (1994) A global conformance quality model. A new strategic tool for minimizing defects caused by variation, error, and complexity. PhD dissertation, Mechanical Engineering Department, Stanford University

33. Antani KR (2014) A Study of the effects of manufacturing complexity on product quality in mixed-model automotive assembly. $\mathrm{PhD}$ dissertation, Mechanical Engineering Department, Clemson University

34. Krugh M, Antani K, Mears L, Schulte J (2016) Prediction of defect propensity for the manual assembly of automotive electrical connectors. Procedia Manuf 5:144-157

35. Falck A-C, Örtengren R, Rosenqvist M, Söderberg R (2017) Proactive assessment of basic complexity in manual assembly: development of a tool to predict and control operator-induced quality errors. Int J Prod Res 55:4248-4260

36. Galetto M, Verna E, Genta G (2020) Accurate estimation of prediction models for operator-induced defects in assembly manufacturing processes. Qual Eng 32:595-613

37. Le Y, Qiang S, Liangfa S (2012) A novel method of analyzing quality defects due to human errors in engine assembly line. In: Information Management, Innovation Management and Industrial Engineering (ICIII), 2012 International Conference on Information Management, Innovation Management and Industrial Engineering (ICIII). IEEE, 20-21 October 2012, Sanya, China, pp 154-157

38. Verna E, Genta G, Galetto M, Franceschini F (2021) Defect prediction models to improve assembly processes in low-volume productions. Procedia CIRP 97:148-153

39. Psarommatis F, May G, Dreyfus P-A, Kiritsis D (2020) Zero defect manufacturing: state-of-the-art review, shortcomings and future directions in research. Int J Prod Res 58:1-17

40. Alkan B (2019) An experimental investigation on the relationship between perceived assembly complexity and product design complexity. Int J Interact Des Manuf 13:1145-1157

41. Sinha K (2014) Structural complexity and its implications for design of cyber-physical systems. PhD dissertation, Engineering Systems Division, Massachusetts Institute of Technology

42. Nikiforov V (2007) The energy of graphs and matrices. J Math Anal Appl 326:1472-1475

43. Li X, Shi Y, Gutman I (2012) Hyperenergetic and Equienergetic Graphs. Graph energy. Springer, New York, pp 193-201

44. Verna E, Genta G, Galetto M, Franceschini F (2021) Defect prediction for assembled products: a novel model based on the structural complexity paradigm. Submitted to J Intell Manuf

45. See JE (2012) Visual inspection: a review of the literature. Sandia Rep SAND2012-8590, Sandia Natl Lab Albuquerque, New Mex

46. Bress T (2017) Heuristics for managing trainable binary inspection systems. Qual Eng 29:262-272

47. Ko J, Nazarian E, Wang H, Abell J (2013) An assembly decomposition model for subassembly planning considering 
imperfect inspection to reduce assembly defect rates. J Manuf Syst 32:412-416

48. Sarkar B, Saren S (2016) Product inspection policy for an imperfect production system with inspection errors and warranty cost. Eur J Oper Res 248:263-271

49. Tang K, Schneider H (1987) The effects of inspection error on a complete inspection plan. IIE Trans 19:421-428

50. Duffuaa SO, Khan M (2005) Impact of inspection errors on the performance measures of a general repeat inspection plan. Int $\mathrm{J}$ Prod Res 43:4945-4967

51. Galetto M, Verna E, Genta G, Franceschini F (2020) Uncertainty evaluation in the prediction of defects and costs for quality inspection planning in low-volume productions. Int J Adv Manuf Technol 108:3793-3805

52. De Ruyter AS, Cardew-Hall MJ, Hodgson PD (2002) Estimating quality costs in an automotive stamping plant through the use of simulation. Int J Prod Res 40:3835-3848

53. Avinadav T, Perlman Y (2013) Economic design of offline inspections for a batch production process. Int J Prod Res 51:3372-3384
54. JCGM 100:2008 (2008) Evaluation of Measurement Data—guide to the Expression of Uncertainty in Measurement (GUM). JCGM, Sèvres, France

55. Ver Hoef JM (2012) Who invented the delta method? Am Stat $66: 124-127$

56. Zeleny M (2011) Multiple criteria decision making (MCDM): from paradigm lost to paradigm regained? J Multi-Criteria Decis Anal 18:77-89

57. Guo S, Zhao H (2017) Fuzzy best-worst multi-criteria decisionmaking method and its applications. Knowledge Based Syst 121:23-31

58. Ishizaka A, Nemery P (2013) Multi-criteria decision analysis: methods and software. Wiley, Hoboken

59. Bhushan N, Rai K (2007) Strategic decision making: applying the analytic hierarchy process. Springer, London

Publisher's Note Springer Nature remains neutral with regard to jurisdictional claims in published maps and institutional affiliations. 